\title{
Ozenoxacin: a review of absorption, dermal exposure and toxicity, tolerability \\ and safety studies
}

\author{
"Preclinical tests have shown that ozenoxacin possesses \\ potent bacteriostatic and bactericidal activity against \\ Gram-positive pathogens..."
}

\section{Future}

MICROBIOLOGY

\section{Savion Gropper*}

Topical antibacterials are useful agents for the management of soft-tissue infections such as impetigo, particularly when compared with systemic therapy, as they avoid unnecessary exposure to the gut flora, which may exert selection for resistance. Topical antibacterials are also easy to use and, as shown in a recent Cochrane systematic review, are at least as effective as systemic agents [1-3]. Furthermore, it is expected that the high dermal drug concentrations associated with local application and the negligible systemic absorption observed in most cases should overwhelm many mutational resistances and therefore be less likely than systemic therapy to cause adverse effects [4]. However, escalating numbers of Gram-positive pathogens, especially Staphylococcus aureus, are becoming increasingly resistant to the leading topical antimicrobials used in clinical practice. For instance, resistance rates to mupirocin (a topical antimicrobial agent) have been reported for $S$. aureus, ranging from $1.3 \%$ in Latin America to $8.7 \%$ in Europe. Mupirocin resistance increases in coagulase-negative staphylococci, with reported rates ranging from $12.7 \%$ in Europe to $38.8 \%$ in the USA [5]. Moreover, several strains of $S$. aureus are also resistant to methicillin, and methicillin-resistant $S$. aureus infections are becoming a major concern worldwide. The increasing incidence of community-acquired methicillin-resistant $S$. aureus infections and resistance to other topical antibacterials justifies the need for alternative therapies for the treatment of skin and soft-tissue infections.

Ozenoxacin is a novel, nonfluorinated quinolone formulated for topical use. Preclinical tests have shown that ozenoxacin possesses potent bacteriostatic and bactericidal activity against Gram-positive pathogens such as $S$. aureus and Streptococcus pyogenes, organisms that are frequently associated with skin and soft-tissue infections [6-8]. These studies indicated that a simplified once- or twice-daily treatment schedule was feasible and should be advantageous in terms of improving compliance and minimizing the risk of treatment failure and the development of resistant strains.

In the studies presented in this supplement, the aim has been to address a number of important questions regarding the pharmacokinetic profile (absorption and dermal exposure), dermal tolerability and safety (irritation, sensitization, phototoxicity and photoallergy) and overall tolerability and safety (adverse events) of ozenoxacin, which is currently in development for the topical treatment of various uncomplicated skin and skin structure infections.

\section{Financial \& competing interests disclosure}

$S$ Gropper is a full-time employee of Ferrer Internacional SA. The author has no other relevant affliations or financial involvement with any organization or entity with a financial interest in or financial conflict with the subject matter or materials discussed in the manuscript apart from those disclosed.

Writing assistance was provided by Content Ed Net, with funding provided by Ferrer Internacional SA.

*Ferrer Internacional SA, Av. Diagonal 549, 5th Floor, 08029 Barcelona, Spain; and Pharmacology, Therapeutics \& Toxicology Department, Universtitat Autonoma de Barcelona, Barcelona, Spain; Tel.: +34 935093 255; Fax: +34 934111 981; saviongropper@yahoo.es

Future : Medicine ${ }_{\text {part of }}$ 


\section{References}

1 Koning S, van der Sande R, Verhagen AP et al. Interventions for impetigo. Cochrane Database Syst. Rev. 1, CD003261 (2012).

2 Free A, Roth E, Dalessandro $\mathrm{M}$ et al. Retapamulin ointment twice daily for 5 days vs oral cephalexin twice daily for 10 days for empiric treatment of secondarily infected traumatic lesions of the skin. Skin Med. 5, 224-232 (2006).

3 George A, Rubin G. A systematic review and meta-analysis of treatments for impetigo. $\mathrm{Br}$. J. Gen. Pract. 53, 480-487 (2003).
4 Leyden JJ. The role of topical antibiotics in dermatologic practice (2003) www.medscape.com/viewprogram/2501

5 Deshpande LM, Fix AM, Pfaller MA, Jones RN. SENTRY Antimicrobial Surveillance Program Participants Group. Emerging elevated mupirocin resistance rates among staphylococcal isolates in the SENTRY Antimicrobial Surveillance Program (2000): correlations of results from disk diffusion, Etest and reference dilution methods. Diagn. Microbiol. Infect. Dis. 42, 283-290 (2002).

6 Yamakawa T, Mitsuyama J, Yamashiro Y. Invitro and in vivo antibacterial activity of
T-3912, a novel non-fluorinated topical quinolone. J. Antimicrob. Chemother. 49, 455-465 (2002).

7 López Y, Tato M, Espinal P et al. In vitro activity of ozenoxacin against quinolonesusceptible and quinolone-resistant Gram-positive bacteria. Antimicrob. Agents Chemother. 57, 6389-6392 (2013).

8 Tato M, López Y, Morosini MI et al. Characterization of variables that may influence ozenoxacin in susceptibility testing, including MIC and MBC values. Diagn. Microbiol. Infect. Dis. 78, 263-267 (2014). 